\title{
EFFECTIVENESS OF STIMULATION OF ENDORPHIN, OXYTOCIN, AND SUGGESTIVE MASSAGE METHOD ON THE BREAST MILK PRODUCTION IN POSTPARTUM MOTHERS AT GENERAL HOSPITAL, SOUTH TANGERANG, BANTEN
}

\author{
Dewi Susanti, Yuliwati \\ Program Study of Diploma-III Midwifery, Academy of Midwifery Karya Bunda Husada
}

\begin{abstract}
Background: The rate of exclusive breastfeeding in Indonesia reduced to $50 \%$ in 2019 , far from the national target of $80 \%$ in 2014. One of the contributing factors is the inadequate breastmilk production of mothers, especially in the first and second days after birth. This study aimed to examine the effectiveness of stimulation of endorphin, oxytocin, and suggestive (SPEOS) massage method on breast milk production in postpartum mothers at General Hospital, South Tangerang, Banten.

Subjects and Method: A randomized control trial was conducted at General Hospital, South Tangerang, Banten, from July to August 2020. A sample of 80 postpartum mothers was randomized into two groups: (1) Experimental group that received SPEOS massage method conducted for 10 minutes, and (2) Control group that received no intervention allocated into two groups. The dependent variable was the production of breastmilk. The independent variable was massage with the SPEOS method. The data were collected by measuring the volume (ml) of breastmilk. The data were analyzed by Mann-Whitney test.

Results: After the intervention, mean of breastmilk production in postpartum mothers in the experimental group (Mean=46.55) was higher than the control group (Mean=34.45), and it was statistically significant $(\mathrm{p}=0.018)$.

Conclusion: Breastmilk production in postpartum mothers increases with the stimulation of endorphin, oxytocin, and suggestion massage method.
\end{abstract}

Keywords: SPEOS, massage, breastmilk production, postpartum mothers

\section{Correspondence:}

Dewi Susanti. Program Study of Diploma-III Midwifery, Academy of Midwifery Karya Bunda Husada. Email: zafrinadewi@gmail.com. Mobile: +6285213230340. 